\title{
Keratinocyte growth factor improves alterations of lung permeability and bronchial epithelium in allergic rats
}

\author{
I. Tillie-Leblond*, ${ }^{\star}$, P. Gosset*, ${ }^{*}$, R. Le Berre" ${ }^{\#}$, A. Janin`, T. Prangère ${ }^{+}$, \\ A.B. Tonnel* and B.P.H. Guery ${ }^{\#}$
}

ABSTRACT: Chronic allergic asthma is associated with marked inflammatory reaction, microvascular leakage and epithelium injury. As previously shown in a rat model of chronic asthma, these alterations increase lung permeability and distal airway fluid clearance. Keratinocyte growth factor (KGF) has been shown to induce epithelial cell proliferation and to protect from acute lung injuries. Therefore, the current authors evaluated the potential role of KGF treatment on lung permeability and airway inflammation in rats with chronic asthma.

KGF (1 $\left.\mathrm{mg} \cdot \mathrm{kg}^{-1}\right)$ was administered intravenously before the last ovalbumin (OVA) challenge in sensitised rats. Permeability was assessed by the leak of radiolabelled albumin from the alveolar and systemic compartments. Histopathological analysis was also performed.

Treatment with KGF decreased the leak of both markers and decreased the level of extravascular lung water in sensitised rats challenged with OVA. KGF treatment also reduced the inflammatory cell number in bronchoalveolar lavage fluid but not in bronchial mucosa. KGF markedly limited the allergen-induced alterations in epithelium integrity and the expression of the intercellular junction proteins $\beta$-catenin and zonula occludens protein-1.

In conclusion, keratinocyte growth factor administration markedly limits lung permeability and airway inflammation, an effect associated with a decrease in epithelium alterations during chronic allergic asthma. These data open new prospects in the therapeutic strategy of asthma.

KEYWORDS: Asthma, growth factor, inflammation, lung permeability, rat

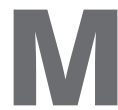
icrovascular leakage represents a classical feature in the pathogenesis of asthma [1]. Many studies have previously shown that an active exsudation involving both the epithelial layer and lamina propria of the bronchial wall associated with hyperplasia of smooth muscle is responsible for the airway obstruction [2-4]. The mechanisms responsible for this exsudation are probably multifactorial but certainly involve an increase in epithelium and endothelium permeability [5]. The current authors have recently studied lung permeability and lung fluid movement in chronic bronchial allergic inflammation and showed that the increased permeability is associated with a tumour necrosis factor (TNF)- $\alpha$-dependent upregulation of distal airway fluid clearance [6]. The modulation of this response could represent an attractive research pathway in asthma treatment. Indeed, alveolar epithelial repair is critical in acute lung injury and the acceleration of this process at an early stage could represent a major therapeutic target.
Keratinocyte growth factor (KGF) is a heparinbinding growth factor [7] which has been shown to have a protective effect in acute lung injury [8, 9]. KGF stimulates both in vitro and in vivo alveolar type II cell proliferation and differentiation $[10,11]$; its activity was first thought to be limited to epithelial cells [12]. This hypothesis was challenged by GILLIS et al. [13], who demonstrated that KGF induces neovascularisation in the rat cornea and protects the endothelium from hydrogen peroxide toxicity. The protective effect of KGF is multifactorial. The current authors have shown, in $\alpha$-naphthylthiourea-induced lung injury, a potentiation of alveolar fluid clearance through sodium-potassium-adenosine triphosphatase stimulation [14]. In Pseudomonas aeruginosa pneumonia, KGF restored lung liquid clearance related to an improvement of the endothelial barrier [15]. An anti-apoptotic effect of KGF is evidenced in hepatocytes after TNF- $\alpha$ injury [16] and finally, in oxidant lung injury, KGF protects alveolar epithelial cells through enhanced DNA repair and prevents the disruption of tight junctions
AFFILIATIONS

*INSERM U774, Institut Pasteur, Lille- and Université de Lille II,

\#Laboratory of Infectious Pathology Research, and

+Laboratory of Biophysics, CHRU de Lille, Lille, and

"Laboratory of Pathology, U728 Inserm, Université Paris 7, Hopital Saint Louis, Paris, France. §. Tillie-Leblond and P. Gosset contributed equally to this manuscript.

CORRESPONDENCE

P. Gosset

INSERM U774

Institut Pasteur

1 rue Calmette

BP245

59019-Lille Cedex

France

Fax: 33320877345

E-mail: philippe.gosset@ pasteur-lille.fr

Received:

January 252006

Accepted after revision:

March 222007

STATEMENT OF INTEREST

None declared.

European Respiratory Journal Print ISSN 0903-1936 Online ISSN 1399-3003 
$[17,18]$. KGF also influences the inflammatory response. In acid aspiration lung injury, KGF pre-treatment decreases macrophage inflammatory protein- $2 \alpha$ concentrations and neutrophil recruitment [19]; it has also been shown that KGF can decrease transcripts for many interferon-induced genes [20]. In vitro, KGF downregulates intercellular adhesion molecule-1 and vascular cell adhesion molecule-1 expression on bronchial epithelial cells, leading to a decreased granulocyte adherence to these cells [21].

Therefore, the aim of the present study was to evaluate the effect of KGF in the late stages of ovalbumin (OVA)-induced chronic asthma in brown Norway rats. KGF was injected intravenously, on three consecutive days prior to the last OVA challenge (out of six). The current authors evaluated the effect of this treatment on lung permeability, inflammatory response and on the epithelium alteration associated with the allergic reaction. The current authors also measured the impact of KGF treatment on the inflammatory response and on the bronchial and alveolar repair 7 days after the last challenge.

\section{METHODS}

\section{Animals}

Specific pathogen-free male brown Norway rats (280-300 g, Centre d'élevage Dépré, St Doulchard, France) were housed in the Lille University Animal Care Facility (Lille, France) and allowed food and water ad libitum. All experiments were performed with approval of the Lille Institutional Animal Care and Use Committee. A total of 44 rats were used for all the experiments.

\section{KGF injection}

For the i.v. injection, animals were anaesthetised with sevoflurane (Servorane ${ }^{\mathrm{TM}}$; Abbott, Maidenhead, UK) and the injection was performed once in the dorsal penile vein, on each of the three consecutive days prior to the experimental study. Either KGF (recombinant human KGF $1 \mathrm{mg} \cdot \mathrm{kg}^{-1}$ in $1 \mathrm{~mL}$ PBS; Amgen, Thousand Oaks, CA, USA) or an equal volume of isotonic saline was injected; the animal was then allowed to recover. An effective dose was established in models of lung injury [14, 15].

\section{Immunisation and exposure to OVA}

Rats were immunised to OVA on the first and fifteenth days by i.p. injection with $10 \mu \mathrm{g}$ OVA associated with $1.5 \times 10^{10}$ heatkilled Bordetella pertussis organisms and $1 \mathrm{mg} \mathrm{Al}_{2} \mathrm{O}_{3}$ (Vaxicoq; Institut Mérieux, Lyon, France) [22]. Control animals were injected on day 1 and 15 with $0.5 \mathrm{~mL}$ of sterile isotonic saline.

Animals were exposed for $20 \mathrm{~min}$ to aerosolised OVA (1\% weight for volume) or sterile saline in an inhalation chamber [22]. The aerosol was generated into the chamber with an ultrasonic nebuliser (Pariboy, Starnberg, Germany). Rats were exposed to a total of six nebulisations with OVA solution, or sterile saline for controls, for the first time on day 21 (6 days after the last OVA i.p. injection) and on days 25, 29, 33, 37 and 41.

\section{Histopathology}

Lung and bronchial samples from each group were analysed. The sample was fixed in formaldehyde and embedded in paraffin. Paraffin sections were stained with haematoxylin and eosin and by May-Grünwald Giemsa (MGG; Sigma-Aldrich, St
Quentin en Fallavier, France) for analysis of inflammatory cells. Cells were counted (eosinophils, neutrophils and mononuclear cells) by two independent observers and expressed by high power field $(\times 100)$. Four fields, preferentially selected on peribronchial, peribronchiolar and perivascular areas, were evaluated for each section. The epithelial integrity was also determined using computer-assisted morphometry (IM500; Leica Microsystems, Heerbrugg, Switzerland) as the percentage of bronchial epithelium length with desquamated (lack of epithelial cell on the basement membrane) or damaged (shrinkage, thinning down, detachment) epithelium.

Immunohistochemistry analyses for $\beta$-catenin and zonula occludens (ZO)-1, two adaptor proteins required for the formation of adherens and tight junctions, respectively, were performed on paraffin-embedded lung sections. First, sections were deparaffinised and treated for antigen retrieval by incubation at $90^{\circ} \mathrm{C}$ for $20 \mathrm{~min}$ in citrate buffer. Then, the sections were incubated with rabbit immunoglobulin (Ig)G, anti- $\beta$-catenin (Santa-Cruz Biotechnology, San Diego, CA, USA) and anti-ZO-1 (Invitrogen, Paisley, UK) at a concentration of $2 \mu \mathrm{g} \cdot \mathrm{mL}^{-1}$ in PBS with $2 \%$ foetal calf serum. After washings, the binding was detected by incubation with biotinylated anti-rabbit IgG goat IgG (Sigma-Aldrich) and then with the $\mathrm{ABC}$-alkaline phosphatase kit (Vector, Burlingame, CA, USA). Enzymatic activity was revealed in red with Fast Red and sections were counter-stained with haematoxylin (Sigma-Aldrich).

\section{In vivo measurement of the alveolar permeability}

\section{Surgical preparation and ventilation}

As previously described [15], male brown Norway rats were anaesthetised with pentobarbital (Sanofi, Libourne, France). A catheter (PE-50) was inserted into the left carotid artery to monitor systemic arterial pressure and obtain blood samples. Pancuronium bromide $\left(0.3 \mathrm{mg} \cdot \mathrm{kg}^{-1} \cdot \mathrm{h}^{-1}\right.$ i.v. $)$ was given to achieve neuromuscular blockade. An endotracheal tube (PE220) was inserted via tracheostomy. The rats were ventilated with a constant volume pump (Harvard Apparatus, South Natick, MA, USA) with an inspired oxygen fraction of 1.0, peak airway pressures of $0.78-1.2 \mathrm{kPa}\left(8-12 \mathrm{cmH}_{2} \mathrm{O}\right)$ and a positive end expiratory pressure of $0.20 \mathrm{kPa}\left(2 \mathrm{cmH}_{2} \mathrm{O}\right)$.

\section{Preparation of instillate}

The test solution used for alveolar instillation was prepared as follows: briefly, a $5 \%$ bovine albumin solution was prepared using Ringer lactate $[6,15,23]$. To the $5 \%$ albumin solution, $1 \mu \mathrm{Ci}$ of ${ }^{125} \mathrm{I}$-labelled human serum albumin $\left({ }^{125} \mathrm{I}-\mathrm{HSA}\right.$; CIS biointernational, Gif sur Yvette, France) was added. Also, anhydrous Evan's blue dye $(0.5 \mathrm{mg})$ was added to confirm the location of the instillate at the end of the study. A sample of the instilled solution was saved for total protein measurement, radioactivity counts and water/dry weight ratio measurements.

\section{General protocol}

For all experiments, the following general protocol was used. After the surgical preparation, heart rate and blood pressure were allowed to stabilise for $1 \mathrm{~h}$. The rat was then placed in the left lateral decubitus position (to facilitate liquid deposition into the left lung). 
To calculate the flux of plasma protein into the lung interstitium, a vascular tracer, $1 \mu \mathrm{Ci}$ of ${ }^{131} \mathrm{I}-\mathrm{HSA}$, was injected into the bloodstream [6, 23]. ${ }^{131}$ I-HSA was prepared in the current authors' institution according to a standardised technique [24]. To calculate the flux of protein from the airspaces into the circulating plasma, $3 \mathrm{~mL} \cdot \mathrm{kg}^{-1}$ of the $5 \%$ bovine albumin solution with $1 \mu \mathrm{Ci}$ of ${ }^{125} \mathrm{I}-\mathrm{HSA}$ was instilled $30 \mathrm{~min}$ later into the left lung over a 10-min period, using a 1-mL syringe and polypropylene tube (0.5 $\mathrm{mm}$ internal diameter) [25].

The abdomen was opened $1 \mathrm{~h}$ after the beginning of the alveolar instillation and the rat was bled. Urine was sampled for radioactivity counts. The lungs were removed via sternotomy, and fluid from the distal airspaces was obtained by passing a propylene tube $(0.5 \mathrm{~mm}$ internal diameter $)$ into a wedged position in the left lower lobe. The total protein concentration and the radioactivity of the liquid sampled were measured. Right and left lungs were homogenised separately for water/dry weight ratio measurements and radioactivity counts.

\section{Haemodynamics, pulmonary gas exchange and protein concentration}

Systemic arterial pressure and airway pressures were measured continuously. Arterial blood gases were measured at 1-h intervals. The arterial oxygen tension was used to quantify the oxygenation deficit $[6,23,26]$. Samples from instilled protein solution, final distal airspace fluid and from initial and final blood were collected to measure total protein concentration with an automated analyser (Hitachi 917; Hitachi, Tokyo, Japan).

Albumin flux across endothelial and epithelial barriers

Two different methods were used to measure the flux of albumin across the lung endothelial and epithelial barriers. The first method measures residual ${ }^{125} \mathrm{I}$-HSA (the alveolar protein tracer) in the lungs and accumulation of ${ }^{125} \mathrm{I}-\mathrm{HSA}$ in plasma. The second method measures ${ }^{131}$ I-HSA (the vascular protein tracer) in the extravascular spaces of the lungs, as previously described [6].

\section{Bronchoalveolar lavage}

Lungs from each experimental group were lavaged with a total of $30 \mathrm{~mL}$ of PBS with $3 \mathrm{mM}$ EDTA in 5-mL aliquots. Total and differential cell count was determined after MGG staining by counting 300 cells sample ${ }^{-1}$ and results were expressed for each cell type as the percentage of total cell number.

\section{Experimental protocols}

The following experimental groups were studied for analysis of permeability and pathological analysis. Group C: rats immunised and challenged by sterile saline, analysed at day $43(n=9)$; group Se: rats immunised with OVA and shamchallenged, analysed at day $43(\mathrm{n}=9)$; group OVA: rats immunised and challenged with OVA, analysed at day 43 $(n=9)$; group KOVA: rats immunised and challenged with OVA, analysed at day 43, KGF administered intravenously ( $1 \mathrm{mg}$ at day 38,39 and $40 ; \mathrm{n}=9$ ). Two additional experimental groups were devoted only to histological analysis. Group ROVA: rats immunised and challenged with OVA, analysed at day $50(n=4)$; group KROVA: similar to the KOVA, but analysed at day $50(n=4)$.
In vivo studies to evaluate permeability of the alveolo-capillary barrier to proteins were performed $24 \mathrm{~h}$ after the last nebulisation on each of the first four groups. Pathological analysis and bronchoalveolar lavage (BAL) were obtained at the same time.

\section{Statistical analysis}

Results are presented as mean \pm SEM. Data were analysed using the Kruskal-Wallis test and the Mann-Whitney U-test where appropriate. A value of $\mathrm{p}<0.05$ was regarded as statistically significant.

\section{RESULTS}

\section{OVA sensitisation is associated with an increase in epithelial and endothelial permeability}

The OVA challenge in sensitised animals (OVA group) is associated with an increase of radiolabelled albumin flux both from the alveolar or the systemic compartments. In fact, the current authors observed an increase of the leak of the alveolar protein tracer, ${ }^{125} \mathrm{I}-\mathrm{HSA}$, into the systemic circulation in the OVA group compared to both the Se and the control groups (fig. 1). Similarly, the evaluation of endothelial permeability using the leak of the vascular tracer, ${ }^{131}$ I-HSA, into the alveoli was consistent with those results (fig. 1). The interstitial compartment was significantly increased in the OVA group compared with the sensitised animals, as reflected by the increase of total interstitial plasma equivalent and lung wet/ dry weight ratio (table 1 ). These results are comparable to previous data obtained by the current authors [6].

\section{KGF pre-treatment improves alterations of permeability observed after OVA sensitisation and challenge test}

Administration of KGF is associated with a decrease of the leak of both markers, ${ }^{125} \mathrm{I}-\mathrm{HSA}$ and ${ }^{131} \mathrm{I}-\mathrm{HSA}$, in the systemic and alveolar compartment, respectively (fig. 1). The interstitial plasma equivalent and the lung wet/dry weight ratio were also significantly lower after KGF treatment compared with the OVA group (100 and 65\% inhibition, respectively; table 1).

\section{KGF pre-treatment inhibits lymphocyte and neutrophil recruitment in BAL}

Compared with control animals, OVA challenge leads to the development of a peribronchial inflammation (figs $2 a$ and $b$ ) and a leukocyte cell influx in the BAL (fig. 3). This cell infiltrate was mainly composed of lymphocytes and granulocytes in the BAL from OVA rats (fig. 3). In addition, the number of eosinophils and mononuclear cells was significantly higher in OVA rats compared with control or with sensitised rats $(p<0.05$; table 2$)$. OVA challenge induced epithelial lesions as illustrated by their shedding in the BAL. In the KOVA group, KGF administration significantly decreased both lymphocyte and neutrophil counts in BAL compared with OVA (fig. 3), whereas there was no significant effect on peribronchial infiltrates (figs $2 \mathrm{~d}$ and e, table 2). Surprisingly, KGF did not affect the OVA-induced recruitment of eosinophils in the BAL and bronchial mucosa. Moreover, histopathological analysis performed 7 days after the last challenge showed that a bronchial inflammatory infiltrate mainly composed of mononuclear cells persisted at a similar level in both rats from the ROVA and KROVA groups, although the difference was not statistically different from the control rats. 

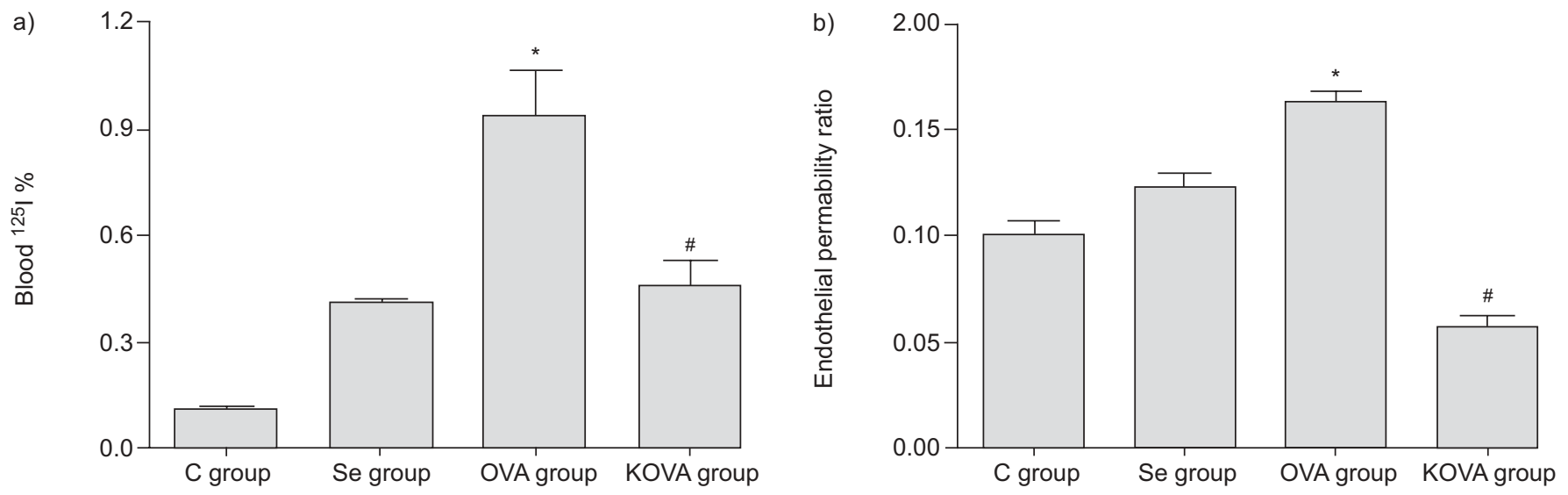

FIGURE 1. a) Measurement of the epithelial permeability assessed with the leak of the alveolar tracer ( ${ }^{125}$-labelled human serum albumin $\left({ }^{125}\right.$-HSA)) in the systemic compartment expressed as a percentage of the total instilled radioactivity. b) Measurement of the endothelial permeability expressed as the ratio of the systemic tracer ( ${ }^{131} \mathrm{I}-\mathrm{HSA}$ ) recovered by bronchoalveolar lavage to the systemic count. C group: immunised and challenged by sterile saline, analysed at day 43; Se group: immunised with ovalbumin (OVA) and sham-challenged, analysed at day 43; OVA group: immunised and challenged with OVA, analysed at day 43; KOVA group: immunised and challenged with OVA, analysed at day 43, keratinocyte growth factor administered ( $1 \mathrm{mg}$ at day 38,39 and 40). *: $p<0.05$ compared with both Se and control groups; $\#$ : $p<0.05$ compared with OVA group

In the BAL, no significant inflammatory cell infiltrate was detected in either the ROVA or KROVA groups.

\section{KGF limits epithelium alterations}

Since KGF mainly targets epithelial cells, the present study focused on the effect of this treatment on epithelial lesions associated with asthma. OVA challenge in sensitised animals induced epithelial damage in the bronchial epithelium as shown in figure $2 \mathrm{a}$ and $\mathrm{b}$ ( $24 \mathrm{~h}$ after the last inhalation). KGF treatment limited these epithelial alterations and restored the epithelial integrity (figs $2 \mathrm{~d}$ and e). Indeed, only $4.3 \%$ of the epithelial surface was altered in the KOVA group compared with $43.4 \%$ in the OVA group $(p<0.05)$. Moreover, a marked decrease of perivascular oedema was observed after KGF administration (figs $2 \mathrm{~g}$ and $\mathrm{h}$ ).

In addition, 7 days after the last challenge, there was a restoration of bronchial epithelium in the KROVA group (7\% damaged epithelial; fig. 2f) whereas restrained epithelial

\begin{tabular}{lcc} 
TABLE 1 & $\begin{array}{l}\text { Effect of keratinocyte growth factor pre-treatment } \\
\text { on wet/dry (W/D) lung weight ratio and interstitial } \\
\text { plasma equivalent }\end{array}$ \\
\hline Group & W/D weight ratio & Interstitial plasma equivalent $\mu$ L \\
\hline C & $3.31 \pm 0.28$ & $0.003 \pm 0.02$ \\
Se & $3.43 \pm 0.22$ & $0.06 \pm 0.02$ \\
OVA & $4.34 \pm 0.29^{*}$ & $0.103 \pm 0.05^{*}$ \\
KOVA & $3.75 \pm 0.31$ & $0.03 \pm 0.018$ \\
\hline
\end{tabular}

Data are presented as mean \pm SEM. C group: immunised and challenged by sterile saline, analysed at day 43; Se group: immunised with ovalbumin (OVA) and sham-challenged, analysed at day 43; OVA group: immunised and challenged with OVA, analysed at day 43; KOVA group: immunised and challenged with OVA, analysed at day 43 , keratinocyte growth factor administered ( $1 \mathrm{mg}$ at day 38,39 and 40 ). *: $\mathrm{p}<0.05$ compared with other groups. alterations persisted in the ROVA group (24\% damaged epithelium).

\section{Expression of protein belonging to the intercellular junctions}

The expression of intercellular junction proteins, $\beta$-catenin and ZO-1 was evaluated by immunohistochemistry. Challenges with OVA in sensitised rats decreased the level of expression for both proteins in epithelial cells in comparison with control rats (fig. 4). KGF treatment strongly increased the level of $\beta$ catenin and ZO-1 expression in both the epithelial cells and the vascular walls as compared with OVA rats. Some cells within the bronchial mucosa are also positive for both proteins in control and KOVA rats. The expression of ZO- 1 and $\beta$-catenin in the KROVA group was similar to that observed in the KOVA group whereas in the ROVA group, the intensity of staining is intermediate between that of the OVA and KOVA groups (data not shown). No staining was detected with the control IgG (fig. 4).

\section{DISCUSSION}

Since microvascular leakage and epithelial alteration represent an important feature in the pathogenesis of severe asthma, the current authors evaluated the effect of treatment with a factor able to facilitate airway mucosa repair, such as KGF. In the present study, it was demonstrated that KGF improves OVAinduced increase in alveolar permeability in the model of allergic bronchial inflammation in brown Norway rats. Moreover, the decrease in epithelial and alveolar permeability is associated with an improvement in epithelial alterations and a decrease in neutrophil and lymphocyte influx in BAL.

Epithelial damage is a characteristic feature of asthma [1]. The epithelium is a barrier but also generates mediators that play a key role in the inflammatory response and remodelling in asthma. Many growth factors such as hepatocyte growth factor, granulocyte-macrophage colony-stimulating factor, transforming growth factor- $\beta$ and epithelial growth factor (EGF) are implicated in this process. EGF stimulates epithelial 

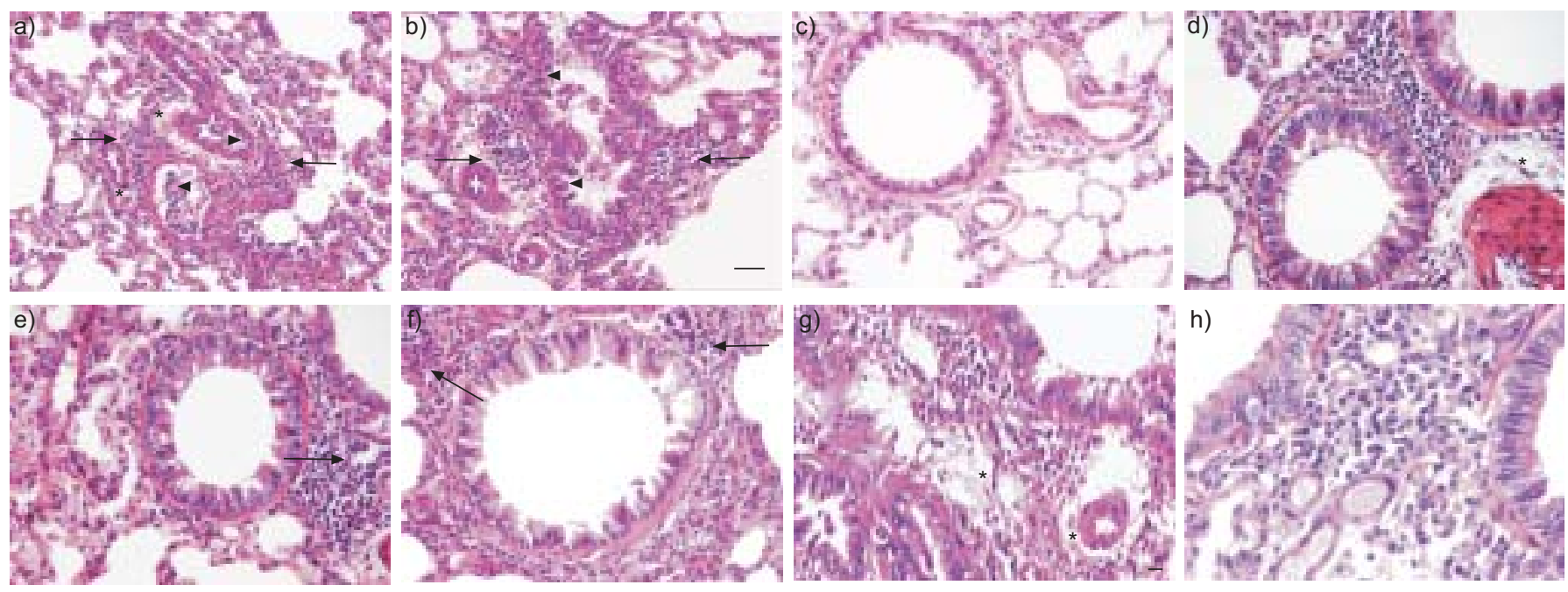

FIGURE 2. Effect of keratinocyte growth factor (KGF) treatment on the peribronchial inflammatory infiltrate and bronchial epithelium alteration in rats sensitised and challenged with ovalbumin (OVA). Paraffin-embedded sections from OVA ( $a$ and b), Se (c), KOVA ( $d$ and e) and KROVA (f) rats were stained with haematoxylin and eosin KGF treatment did not markedly modify the inflammatory infiltrate (arrows) but inhibited the epithelial lesion observed in OVA rats (arrowheads) and allowed a restoration to nearly undamaged epithelium in KOVA rats ( $\mathrm{d}$ and e) and 7 days after the last challenge (f). KGF also decreases perivascular oedema $\left(^{*}\right)$; OVA group ( $\mathrm{g}$ ) versus KOVA group (h). Se group: immunised with OVA and sham-challenged, analysed at day 43; OVA group: immunised and challenged with OVA, analysed at day 43; KOVA group: immunised and challenged with OVA, analysed at day 43, KGF administered ( $1 \mathrm{mg}$ at day 38,39 and 40); KROVA group: similar to the KOVA group, but analysed at day 50 . a-f) Scale bar $=30 \mu \mathrm{m} ; \mathrm{g}, \mathrm{h})$ scale bar $=10 \mu \mathrm{m}$.

cell proliferation and migration. KGF, also called FGF-7, belongs to the family of the fibroblast growth factor and predominantly stimulates the proliferation of epithelial cells [7, $11,12,27,28]$. KGF has been demonstrated to be a potent mitogen of alveolar epithelial type II cells in the lung, and also of bronchial epithelial cells in vitro and in vivo [10, 11, 29]. The protective effect of KGF has been demonstrated in different situations, including the prevention of cell loss but also the repair of the epithelium after injury [14-17].

In asthma, little is known about the role of KGF. The current authors have demonstrated in chronic asthma that the treatment by KGF before the last OVA nebulisation was associated with a decrease of the leak of epithelial and endothelial markers. The effect of KGF on the permeability of airway epithelial cell has already been investigated by WATERS et al. [30]. Indeed, KGF reduces the basal albumin flux and prevents the increase in permeability induced by hydrogen peroxide on airway epithelial cell monolayers. This effect is probably due to changes in paracellular permeability, but not to cell proliferation since the reduction in epithelial permeability was rapidly observed ( $1 \mathrm{~h}$ after KGF addition). One mechanism could be due to the KGF-induced stabilisation of the tight junctions in this model [18]. In the present study, KGF was administered 3 days consecutively before the last challenge, a period which should be sufficient to restore bronchial epithelium in rats. KGF was injected after the fifth challenge with OVA, when important epithelial lesions were observed in the bronchial mucosa of sensitised rats. As shown in figure 2, treatment with KGF markedly limits the alteration of the epithelial barrier with an improvement of the permeability increase. However, with this method, it cannot be determined whether this increase of permeability is related to large or small airways. Both sites are probably involved, since KGF treatment clearly induced small and large bronchial epithelial repair. MiCHELSON et al. [31] also showed in vitro and in vivo that KGF-induced bronchial epithelial cell proliferation in rats, with a dose-dependent increase in DNA synthesis. Since, in the present study, the effect was observed after 3 days treatment, cell proliferation was probably involved in epithelial regeneration in this model. Moreover, both prevention of tight junction disruption and bronchial cell proliferation may act together to limit the increase in lung epithelial permeability induced by allergen. Indeed, the current authors observed that KGF prevents the OVA-induced decreased expression of both ZO-1 and $\beta$-catenin, two adaptors playing a key role in the formation of tight and adherens junctions, respectively. Their expressions were also identified in cell infiltrate within the bronchial mucosa; this might be due to their transient expressions by some inflammatory cells as previously reported [32, 33]. One other function has been assigned to $\beta$-catenin, i.e. that of being a co-activator of transcription factors lymphoid enhancer factor/T-cell factor proteins, a process implicated in cell proliferation and in the production of metalloproteases [34]. ZO-1 might also recruit signalling proteins that participate in the regulation of cell proliferation and differentiation [35]. Additional experiments are required to determine if KGF acts at the transcriptional or at the translational level, and to determine if this KGF-induced upregulation is associated with a re-formation of adherens and tight junctions. Moreover, epithelium restitution was achieved at day 7 after the last challenge, although an inflammatory cell infiltrate persisted within the mucosa. Therefore, these data show that KGF is able to repair epithelial damages and limit the effect of OVA challenge in the present experimental model.

The anatomical level of liquid clearance was not evaluated Most data obtained with the same procedure (labelled tracers) for evaluating the epithelial and alveolar permeability are 
a)

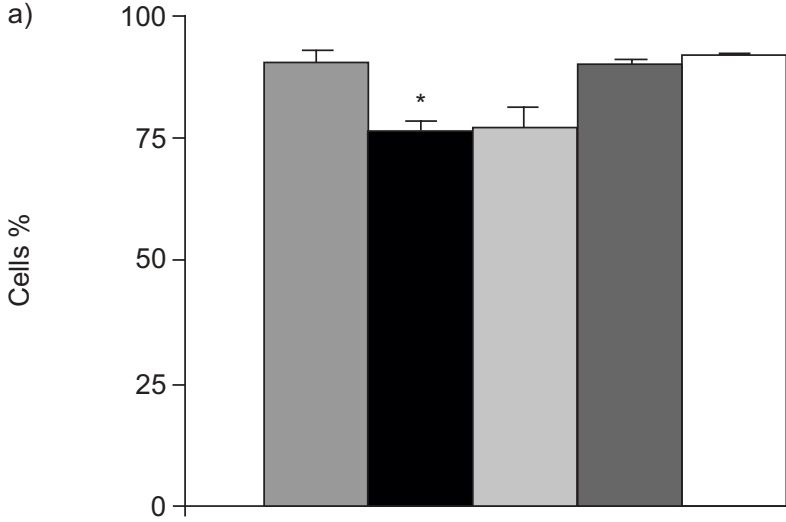

c)

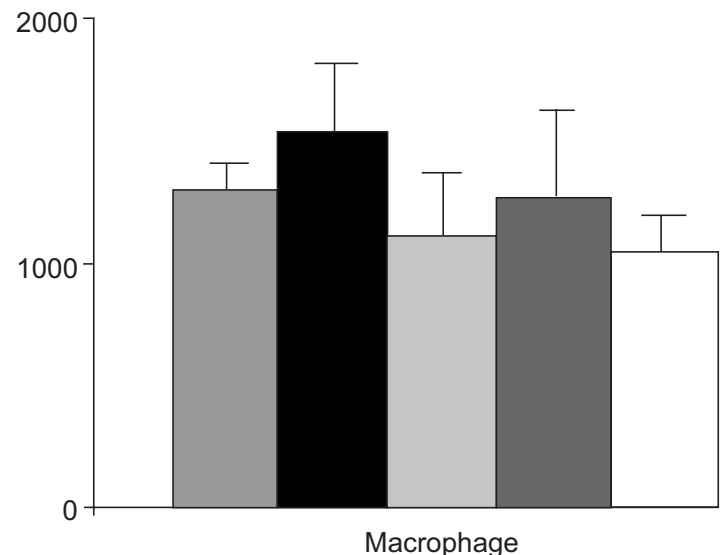

b)

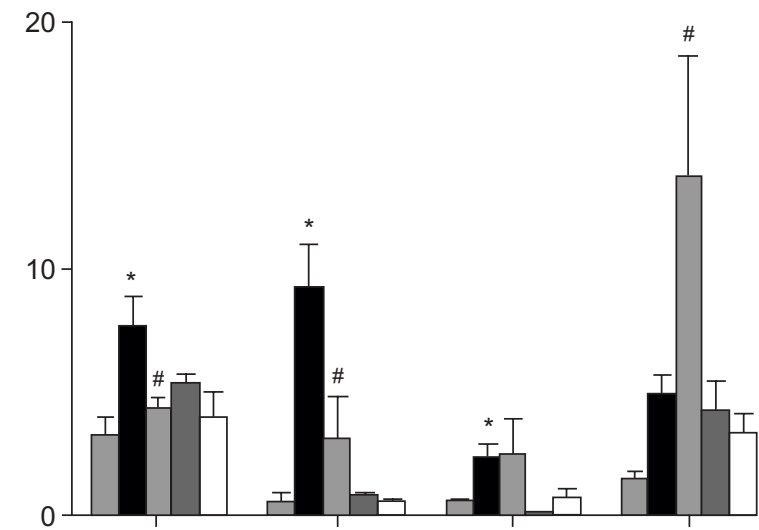

d)

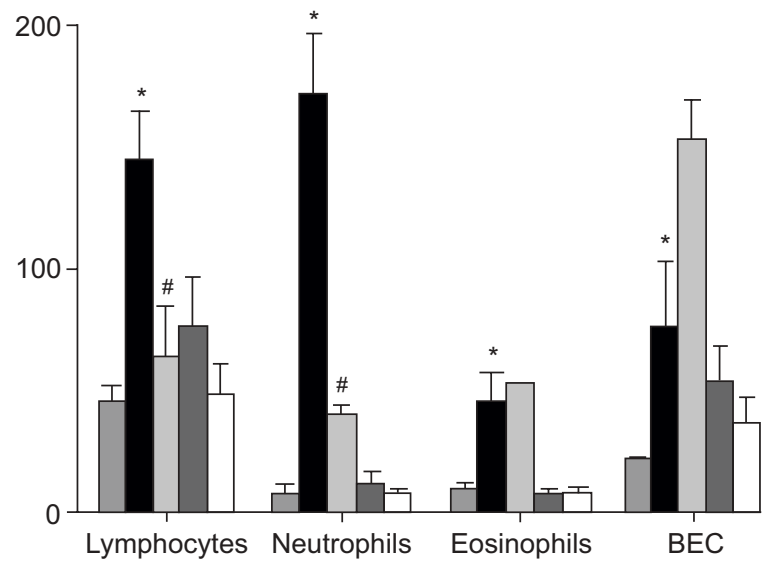

FIGURE 3. Differential cell count analysis in the bronchoalveolar lavage (BAL) from rats sensitised and challenged with saline serum (Se group; $\square$ ), challenged with ovalbumin (OVA; OVA group; $\square$ ) and treated with keratinocyte growth factor (KGF; KOVA group; $\square$ ) collected $24 \mathrm{~h}$ after the last challenge. The BAL procedure was also performed 7 days after the last challenge in rats treated with KGF (KROVA group; $\square$ ) or not (ROVA group; $\square$ ). Treatment with KGF significantly reduced the OVA-induced influx of lymphocytes and neutrophils, and tended to increase the number of bronchial epithelial cells (BEC). Results were expressed as percentage (a and b) or in absolute counts ( $c$ and d). *: $p<0.05$ compared with both Se and C groups; ${ }^{*}: p<0.05$ compared with OVA group. C group: immunised and challenged by sterile saline, analysed at day 43; Se group: immunised with OVA and sham-challenged, analysed at day 43; OVA group: immunised and challenged with OVA, analysed at day 43; KOVA group: immunised and challenged with OVA, analysed at day 43, KGF administered (1 mg at day 38, 39 and 40); KROVA group: similar to the KOVA group, but analysed at day 50; ROVA group: rats immunised and challenged with OVA, analysed at day 50.

issued from the acute respiratory distress syndrome and pneumonia experimental models. Type II pneumocytes seem to be the main cells involved in fluid movement $[14,15,23]$.
Nevertheless, other data obtained in asthmatics has shown that cells issued from bronchiolar mucosa are also potentially involved $[1,3]$. In the current authors' rat model, injection of

TABLE 2 Modulation by keratinocyte growth factor (KGF) pre-treatment of leukocyte infiltrate in bronchial mucosa from allergic rats

\begin{tabular}{|c|c|c|c|}
\hline Group & Mononuclear cells $\times 10^{-2}$ cells $\cdot \mathrm{mm}^{-2}$ & Neutrophils $\times 10^{-2}$ cells $\cdot \mathrm{mm}^{-2}$ & Eosinophils $\times 10^{-2}$ cells $\cdot \mathrm{mm}^{-2}$ \\
\hline Control & $33.2 \pm 17.1$ & $6 \pm 3.32$ & $1.8 \pm 2.68$ \\
\hline Sensitised & $38.83 \pm 8.93$ & $7.17 \pm 3.2$ & $3.5 \pm 2.6$ \\
\hline OVA & $70.83 \pm 10.8^{*}$ & $7.75 \pm 4.85$ & $13.8 \pm 7.73^{\star}$ \\
\hline KOVA & $67.33 \pm 17.2^{*}$ & $8.5 \pm 4.64$ & $9.67 \pm 4.23^{*}$ \\
\hline ROVA & $57.43 \pm 18.2$ & $3.57 \pm 1.81$ & $2.29 \pm 3.9$ \\
\hline KROVA & $56.29 \pm 22.7$ & $4.43 \pm 3.05$ & $1.57 \pm 1.62$ \\
\hline
\end{tabular}

Data are presented as mean \pm SEM. KGF was administered before the last exposure to ovalbumin (OVA), except in control rats. Leukocyte infiltrate was measured $48 \mathrm{~h}$ (OVA and KOVA groups) or 7 days after the last challenge (ROVA and KROVA groups). ${ }^{*}: \mathrm{p}<0.05$ compared with the rats from the control or the sensitised group. OVA group: immunised and challenged with OVA, analysed at day 43; KOVA group: immunised and challenged with OVA, analysed at day 43 , KGF administered (1 mg at day 38, 39 and 40); KROVA group: similar to the KOVA group, but analysed at day 50; ROVA group: rats immunised and challenged with OVA, analysed at day 50 . 

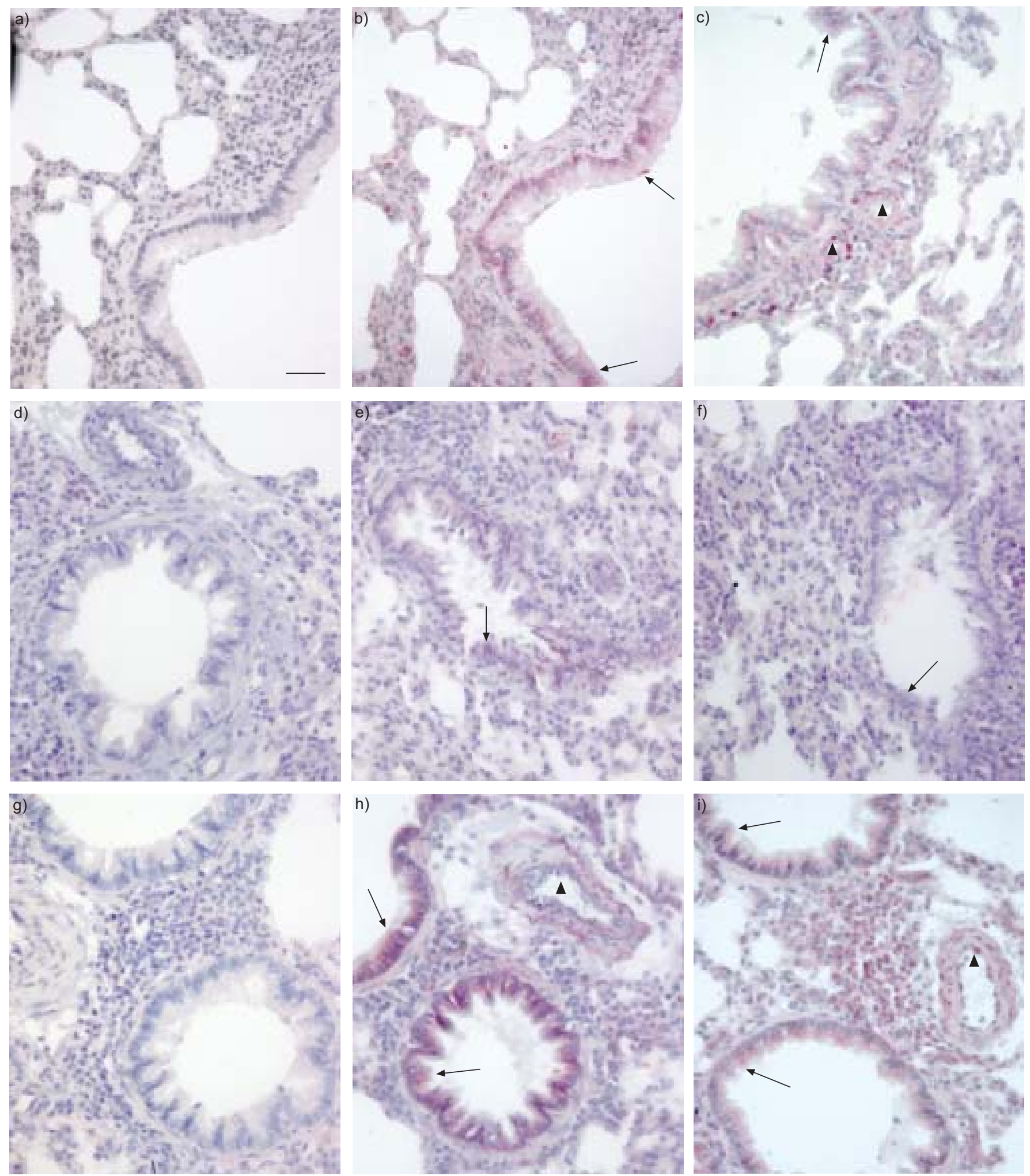

FIGURE 4. Evaluation by immunohistochemistry of the expression of intercellular junction proteins. $b, e, h) \beta$-catenin and $c$, $f$, i) zonula occludens (ZO)- 1 as compared with $\mathrm{a}, \mathrm{b}, \mathrm{c}$ ) the isotype control, nonimmune rabbit immunoglobulin (Ig)G. Lung sections from rats belonging to the a, b, c) control, d, e, f) Ovalbumin (OVA) and g, h, i) KOVA groups were analysed. Positive staining was detected in red and the sections were counterstained with haematoxylin. Both $\beta$-catenin and ZO-1 expression in epithelial cells (arrows) and vascular wall (arrowheads) were expressed in the control and KOVA groups, whereas there is a faint staining in OVA rats. Positive cells were also present within the inflammatory infiltrate. No staining was detected with the nonimmune rabbit lgG. Scale bar $=30 \mu \mathrm{m}$. OVA group: immunised and challenged with OVA, analysed at day 43 KOVA group: immunised and challenged with OVA, analysed at day 43, keratinocyte growth factor administered (1 mg at day 38, 39 and 40). 
$1 \mathrm{~mL}$ into one lung did not allow the localisation of cells involved in liquid clearance.

Endothelial permeability increase is also limited by KGF treatment in asthmatic rats. There are little data concerning the implication of KGF in endothelial cell proliferation. In vivo, KGF induces neovascularisation in the rat cornea [13]. Moreover, it blocks the increase in permeability induced by hydrogen peroxide and vascular endothelial growth factor/ vascular permeability factor in monolayers of microvascular, but not aortic, endothelial cells [13]. KGF is also able to induce angiogenesis and stabilise endothelial barriers in microvascular tissue. In an ex vivo model of hydrostatic pulmonary oedema, KGF attenuates the injury via mechanisms that prevent increases in alveolar-capillary permeability, demonstrating its implication in endothelial permeability [36]. In the model of allergic rats, these data suggest that the action of KGF may implicate a direct effect on endothelial permeability. Since administration of KGF limits lung permeability increase and epithelial alterations associated with repeated OVA challenge in sensitised rats, it can be hypothesised that this treatment affects airway inflammation. Whereas the infiltrate within the bronchial mucosa is not modified, neutrophil and lymphocyte counts decrease in the BAL after KGF administration in rats challenged with OVA. Indeed, KGF has the capacity to limit the production of some chemokines [19]. JUST et al. [21] demonstrated, in vitro, that KGF downregulates the expression of adhesion molecule on epithelial cells; this effect being associated with a decrease in neutrophil adherence. In addition, the increased expression of both $\mathrm{ZO}-1$ and $\beta$-catenin may also limit leukocyte transmigration via the potential reformation of intercellular junctions within the bronchial epithelium.

In conclusion, the present data show that administration of keratinocyte growth factor limits lung permeability increase in the rat model of chronic allergic asthma and limits ovalbumininduced epithelial damage. However, the treatment has a restrained effect on the inflammatory infiltrate within the lung. These observations suggest that such a therapeutic strategy, designed to restore the epithelial and endothelial barrier integrity, may have a great potential to limit the consequences for lung functions of increased permeability in severe asthma. Further studies are necessary to define whether the effects of keratinocyte growth factor might reduce the inflammatory reaction and/or the allergen-specific immune response in the long term.

\section{ACKNOWLEDGEMENTS}

The authors would like to thank J. Kips (Leuven, Belgium) for the help and support he provided in the elaboration of this work, and also to X. Marchandise, P. Briche and N. Zenani (all Lille, France) for their daily encouragements.

\section{REFERENCES}

1 Chung KF, Rogers DF, Barnes PJ, Evans TW. The role of increased airway microvascular permeability and plasma exudation in asthma. Eur Respir J 1990; 3: 329-337.

2 Erjefalt I, Greiff L, Alkner U, Persson CG. Allergeninduced biphasic plasma exudation responses in guinea pig large airways. Am Rev Respir Dis 1993; 148: 695-701.
3 Liu MC, Hubbard WC, Proud D, et al. Immediate and late inflammatory responses to ragweed antigen challenge of the peripheral airways in allergic asthmatics. Cellular, mediator, and permeability changes. Am Rev Respir Dis 1991; 144: 51-58.

4 Yager D, Kamm RD, Drazen JM. Airway wall liquid. Sources and role as an amplifier of bronchoconstriction. Chest 1995; 107: Suppl. 3, 105S-110S.

5 Taylor BM, Kolbasa KP, Chin JE, et al. Roles of adhesion molecules ICAM-1 and $\alpha_{4}$ integrin in antigen-induced changes in microvascular permeability associated with lung inflammation in sensitized brown Norway rats. Am J Respir Cell Mol Biol 1997; 17: 757-766.

6 Tillie-Leblond I, Guery BP, Janin A, et al. Chronic bronchial allergic inflammation increases alveolar liquid clearance by TNF- $\alpha$-dependent mechanism. Am J Physiol Lung Cell Mol Physiol 2002; 283: L1303-L1309.

7 Rubin JS, Osada H, Finch PW, Taylor WG, Rudikoff S, Aaronson SA. Purification and characterization of a newly identified growth factor specific for epithelial cells. Proc Natl Acad Sci USA 1989; 86: 802-806.

8 Atabai K, Ishigaki M, Geiser T, Ueki I, Matthay MA, Ware LB. Keratinocyte growth factor can enhance alveolar epithelial repair by nonmitogenic mechanisms. Am J Physiol Lung Cell Mol Physiol 2002; 283: L163-L169.

9 Ware LB, Matthay MA. Keratinocyte and hepatocyte growth factors in the lung: roles in lung development, inflammation, and repair. Am J Physiol Lung Cell Mol Physiol 2002; 282: L924-L940.

10 Panos RJ, Rubin JS, Csaky KG, Aaronson SA, Mason RJ. Keratinocyte growth factor and hepatocyte growth factor/ scatter factor are heparin-binding growth factors for alveolar type II cells in fibroblast-conditioned medium. J Clin Invest 1993; 92: 969-977.

11 Ulich TR, Yi ES, Longmuir K, et al. Keratinocyte growth factor is a growth factor for type II pneumocytes in vivo. J Clin Invest 1994; 93: 1298-1306.

12 Finch PW, Rubin JS, Miki T, Ron D, Aaronson SA. Human KGF is FGF-related with properties of a paracrine effector of epithelial cell growth. Science 1989; 245: 752-755.

13 Gillis P, Savla U, Volpert OV, et al. Keratinocyte growth factor induces angiogenesis and protects endothelial barrier function. J Cell Sci 1999; 112: 2049-2057.

14 Guery BP, Mason CM, Dobard EP, Beaucaire G, Summer WR, Nelson S. Keratinocyte growth factor increases transalveolar sodium reabsorption in normal and injured rat lungs. Am J Respir Crit Care Med 1997; 155: 1777-1784.

15 Viget NB, Guery BP, Ader F, et al. Keratinocyte growth factor protects against Pseudomonas aeruginosa-induced lung injury. Am J Physiol Lung Cell Mol Physiol 2000; 279: L1199-L1209.

16 Senaldi G, Shaklee CL, Simon B, Rowan CG, Lacey DL, Hartung T. Keratinocyte growth factor protects murine hepatocytes from tumor necrosis factor-induced apoptosis in vivo and in vitro. Hepatology 1998; 27: 1584-1591.

$17 \mathrm{Wu}$ KI, Pollack N, Panos RJ, Sporn PH, Kamp DW. Keratinocyte growth factor promotes alveolar epithelial cell DNA repair after $\mathrm{H}_{2} \mathrm{O}_{2}$ exposure. Am J Physiol 1998; 275: L780-L787.

18 Chapman KE, Waters CM, Miller WM. Continuous exposure of airway epithelial cells to hydrogen peroxide: protection by KGF. J Cell Physiol 2002; 192: 71-80. 
19 Nemzek JA, Ebong SJ, Kim J, Bolgos GL, Remick DG. Keratinocyte growth factor pretreatment is associated with decreased macrophage inflammatory protein- $2 \alpha$ concentrations and reduced neutrophil recruitment in acid aspiration lung injury. Shock 2002; 18: 501-506.

20 Prince LS, Karp PH, Moninger TO, Welsh MJ. KGF alters gene expression in human airway epithelia: potential regulation of the inflammatory response. Physiol Genomics 2001; 6: 81-89.

21 Just N, Tillie-Leblond I, Guery BP, Fourneau C, Tonnel AB, Gosset P. Keratinocyte growth factor (KGF) decreases ICAM-1 and VCAM-1 cell expression on bronchial epithelial cells. Clin Exp Immunol 2003; 132: 61-69.

22 Kips JC, Cuvelier CA, Pauwels RA. Effect of acute and chronic antigen inhalation on airway morphology and responsiveness in actively sensitized rats. Am Rev Respir Dis 1992; 145: 1306-1310.

23 Modelska K, Matthay MA, McElroy MC, Pittet JF. Upregulation of alveolar liquid clearance after fluid resuscitation for hemorrhagic shock in rats. Am J Physiol 1997; 273: L305-L314.

24 Hunter WM, Greenwood FC. Preparation of iodine-131 labelled human growth hormone of high specific activity. Nature 1962; 194: 495-496.

25 McElroy MC, Wiener-Kronish JP, Miyazaki H, et al. Nitric oxide attenuates lung endothelial injury caused by sublethal hyperoxia in rats. Am J Physiol 1997; 272: L631-L638.

26 Pittet JF, Hashimoto S, Pian M, McElroy MC, Nitenberg G, Wiener-Kronish JP. Exotoxin A stimulates fluid reabsorption from distal airspaces of lung in anesthetized rats. Am J Physiol 1996; 270: L232-L241.
27 Rubin JS, Bottaro DP, Chedid M, et al. Keratinocyte growth factor as a cytokine that mediates mesenchymal-epithelial interaction. EXS 1995; 74: 191-214.

28 Werner S, Smola H, Liao X, et al. The function of KGF in morphogenesis of epithelium and reepithelialization of wounds. Science 1994; 266: 819-822.

29 Adamson IY, Young L, Bakowska J. Enhanced alveolar type II cell growth on a pulmonary extracellular matrix over fibroblasts. Am J Physiol 1997; 272: L413-L417.

30 Waters CM, Savla U, Panos RJ. KGF prevents hydrogen peroxide-induced increases in airway epithelial cell permeability. Am J Physiol 1997; 272: L681-L689.

31 Michelson PH, Tigue M, Panos RJ, Sporn PH. Keratinocyte growth factor stimulates bronchial epithelial cell proliferation in vitro and in vivo. Am J Physiol 1999; 277: L737-L742.

32 Rescigno M, Urbano M, Valzasina B, et al. Dendritic cells express tight junction proteins and penetrate gut epithelial monolayers to sample bacteria. Nat Immunol 2001; 2 361-367.

33 Thiele A, Wasner M, Muller C, Engeland K, Hauschildt S. Regulation and possible function of $\beta$-catenin in human monocytes. J Immunol 2001; 167: 6786-6793.

34 Cowin P, Rowlands TM, Hatsell SJ. Cadherins and catenins in breast cancer. Curr Opin Cell Biol 2005; 17: 499-508.

35 Matter K, Aijaz S, Tsapara A, Balda MS. Mammalian tight junctions in the regulation of epithelial differentiation and proliferation. Curr Opin Cell Biol 2005; 17: 453-458.

36 Welsh DA, Guery BP, Deboisblanc BP, et al. Keratinocyte growth factor attenuates hydrostatic pulmonary edema in an isolated, perfused rat lung model. Am J Physiol Heart Circ Physiol 2001; 280: H1311-H1317. 